\section{Military Technical College Kobry El-Kobbah, Cairo, Egypt.}

\section{$15^{\text {th }}$ International Conference on Applied Mechanics and Mechanical Engineering.}

\title{
SIX STROKE ENGINE ARRANGEMENT
}

\author{
M. M. Gasim ${ }^{\star}$, L. G. Chui ${ }^{* \star}$ and K. A. Bin Anwar ${ }^{\star \star \star}$
}

\begin{abstract}
In six stroke engine, there are additional two strokes, namely another power and exhaust strokes. The engine works through harnessing wasted heat energy created by the fuel combustion. After the combustion stage water is injected into the superheated cylinder. The water explodes into steam and force the piston down. It in turn helps to cool the engine. That resulted in normal levels of power but using much less fuel. It also has the advantage of not requiring an external cooling system. In order to achieve these benefits, major modifications of conventional internal combustion engine must be done. In this paper the modification of the conventional four stoke internal combustion engine is illustrated to convert it into six stroke engine.
\end{abstract}

\section{KEY WORDS}

Internal combustion engines, six stroke, water injection.

* Senior lecturer, Faculty of Mech. Eng, Universiti Malaysia Pahang, Kuantan, Malaysia.

** Lecturer, Faculty of Mech. Eng, Universiti Malaysia Pahang, Kuantan, Malaysia.

*** Lab instructor, Faculty of Mech. Eng, Universiti Malaysia Pahang, Kuantan, Malaysia 


\section{INTRODUCTION}

Internal combustion engines efficiency is less than $40 \%$. Most of the energy generated by burning the fuel in the combustion chamber is lost in water cooling and exhaust [1]. Figure 1, below, shows a typical energy split in internal combustion engines.

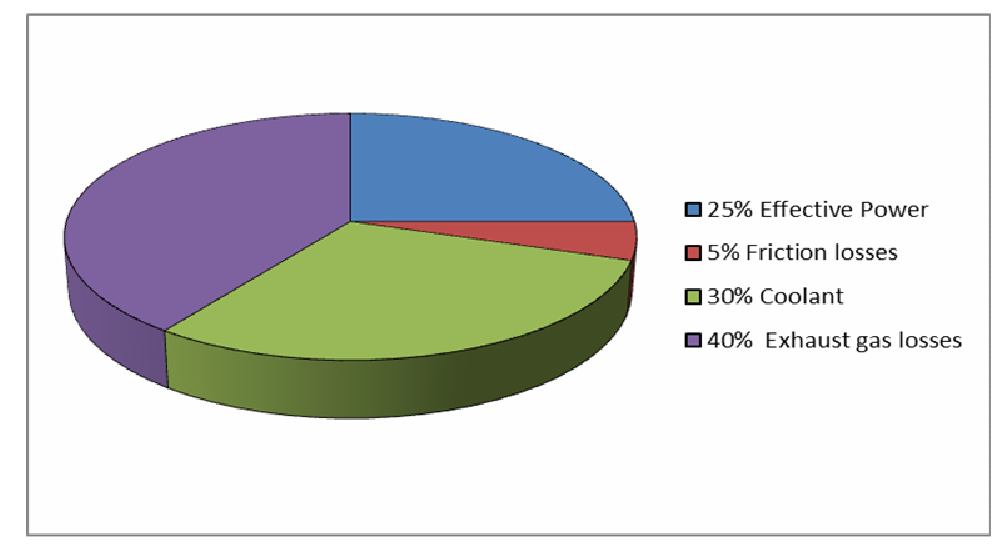

Fig. 1. Energy split in gasoline internal combustion engines.

In 2006, Bruce Crower managed to develop the first six stroke engine. Using a modified single-cylinder diesel engine Crower converted it to use gasoline, and then machined the necessary parts to create the world's only six-stroke engine. The engine works through harnessing wasted heat energy created by the fuel combustion to add other two-strokes to the engine cycle. After the combustion stage water is injected into the super-heated cylinder and a steam form forcing the piston back down and in turn cools the engine. The result is normal levels of power using much less fuel and no need for an external cooling system [2].

There are two methods when operating six stroke engines, the first method by completely finished the exhaust stoke then inject the water. The second method is by trapping and recompression of some of the exhaust from the fourth piston stroke, followed by a water injection and expansion of the resulting steam/exhaust mixture, Figure 2 shows the six stroke engine cycle.

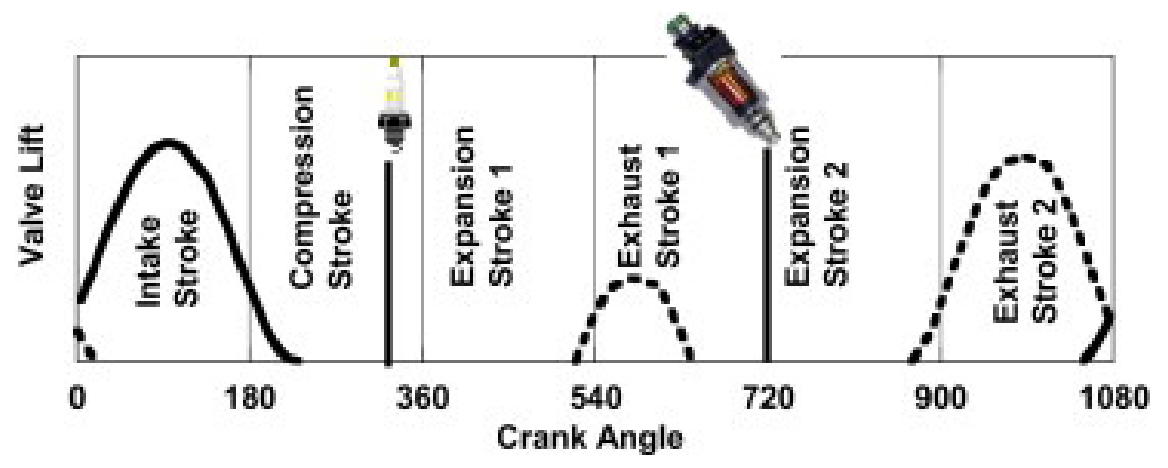

Fig. 2. the six-stroke engine cycle [3]. 
Conklin and Szybist [3] made a theoretical thermodynamics analysis to this six stroke engine with the second method, to calculate the effect of this new arrangement on mean effective pressure. The result from their analysis is shown in Figure 3.

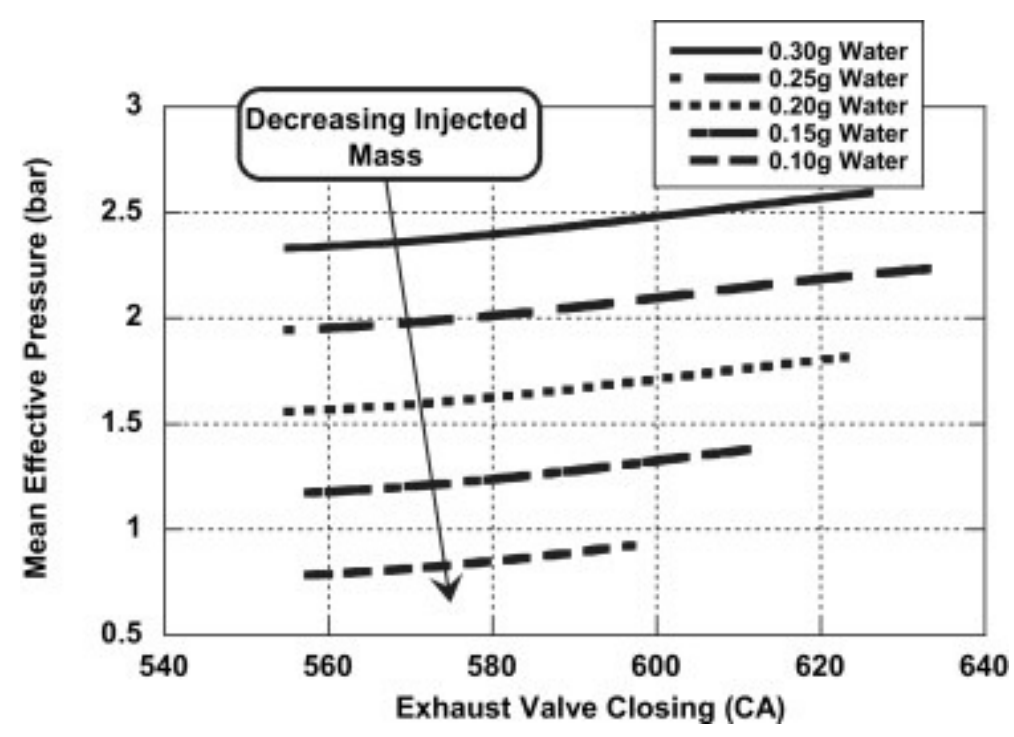

Fig. 3. Mean effective pressure due to second expansion with water injection [3].

Figure 3 shows an increase in mean effective pressure with the increase of amount of water injected and also with more delaying of exhaust valve cam closing.

The starting of six stroke engine was a problem as reported by Andrew De Jong et. al. [4], instead of conventional starter a DC motor was used to start the engine. In this step of the project an experimental test will be done to a single cylinder four stroke internal combustion engine to convert it to six stroke engine just to be sure that the engine can run with six stroke cycles smoothly.

\section{ENGINE MODIFICATION}

To make six-stroke engine from conventional four-stroke engine, a few modifications must be done to specific parts on the conventional engine to be sure that the new engine with six-stroke will run successfully. A Mitsubishi single cylinder spark ignition engine was used to apply these modifications on it. These modifications are:

\section{Crankshaft to Camshaft Ratio Modification}

In conventional four stroke engine, the gear at crankshaft must rotate $720^{\circ}$ while the camshaft rotates $360^{\circ}$ to complete one cycle. For six-stroke engine, the gear at the crankshaft must rotate $1080^{\circ}$ to rotate the camshaft $360^{\circ}$ and complete one cycle. Hence their corresponding gear ratio is $3: 1$.

Figure 4 shows the previous gear at regular engine running in four stroke engine at ratio 2:1 and the new gears to work with six stroke engine. The new gear at the 
crank shaft has 18 teeth and the cam shaft gear has 54 teeth. The type of gear is helical gear because it is suitable for high-speed, high power application and quite at high speed rotation.

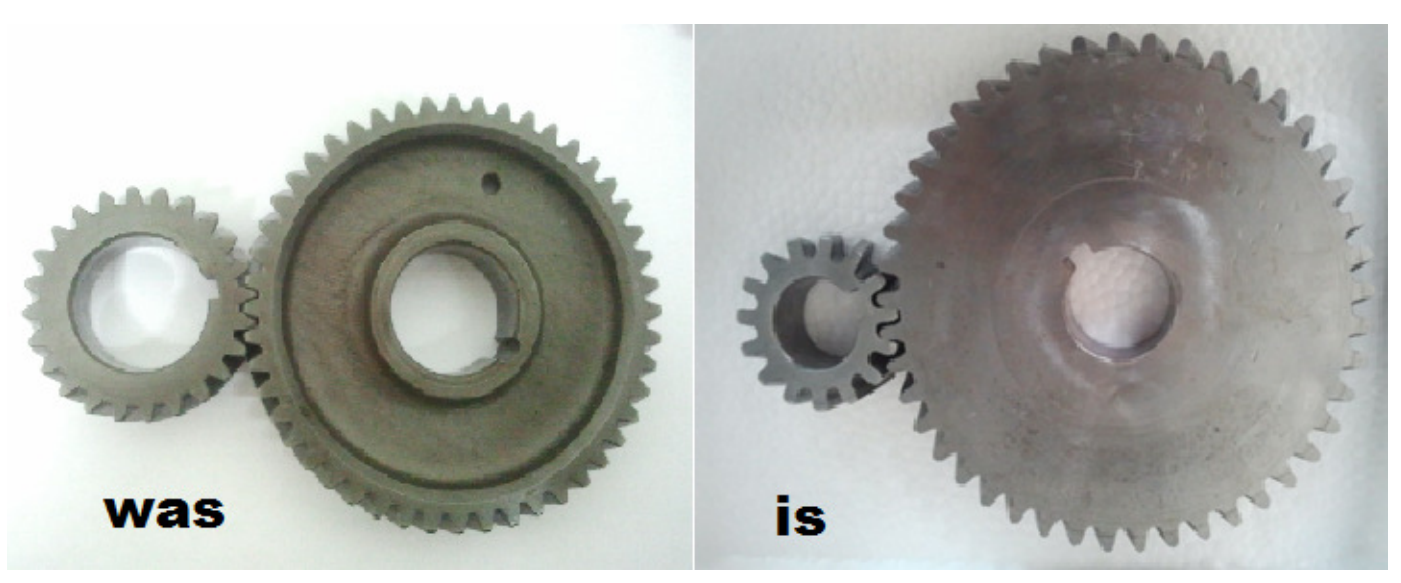

Fig. 4. Crankshaft and camshaft modification.

\section{Camshaft Modification}

In the six stroke engine the 360 degree of the cam has been divided into 60 degree among the six-strokes. The exhaust cam has 2 lobes to open the exhaust valve at fourth stroke (first exhaust stroke) and at the sixth stroke to push out the steam. Figure 5 shows the new cams and the new camshaft.
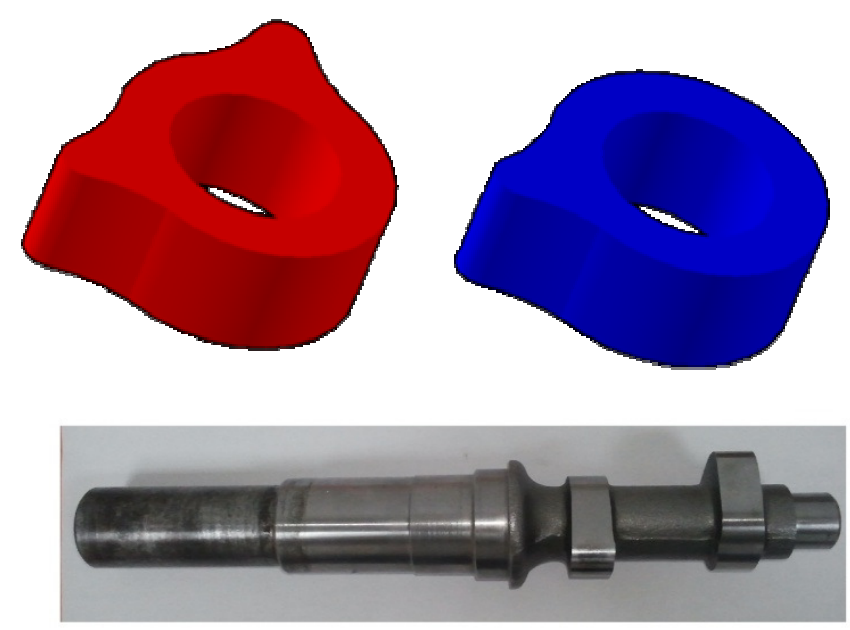

was

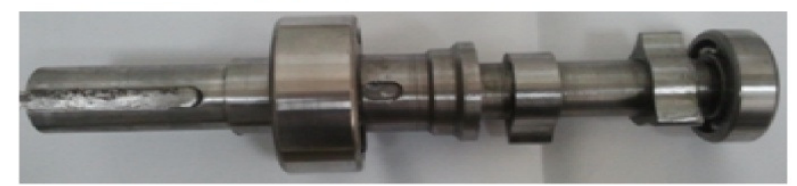

is

Fig. 5. Cams and Camshaft. 


\section{Cam follower modification}

The bottom shape of regular follower has the flat pattern, which is suitable with the normal camshaft for four stroke engine. When reducing the duration of valve opening from $900^{\circ}$ to only $600^{\circ}$ the shape of the follower must be changed from flat to roller or spherical shape. In this case a spherical shape is chosen as seen in Figure 6.

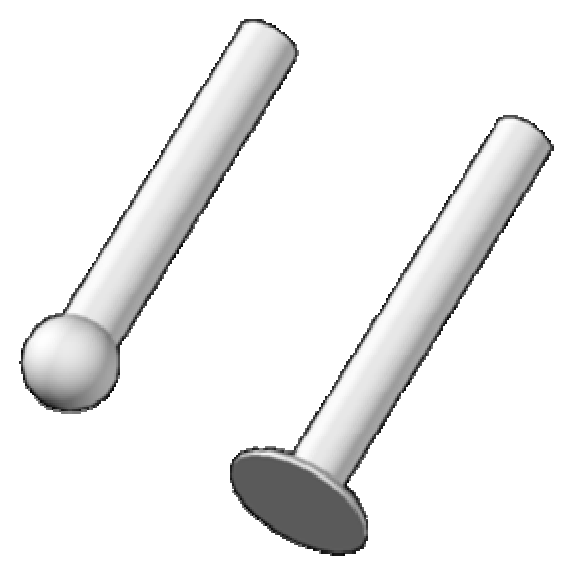

Fig. 6. Flat and spherical followers.

\section{TESTING THE ENGINE}

After applying these modifications on the engine, a test was carried out to be sure that the engine can run smoothly with six stroke instead of four stroke cycles. The same starter coupled with the engine was used to start the engine. After two or three attempts the engine was running smoothly with six stroke cycles.

\section{CONCLUSION}

In this paper the modification required to convert the four stroke conventional engine to six stroke engine is illustrated. The modifications are the gear ratio between the crankshaft and the camshaft and modification of the cam shaft.

The previous efforts done on six stroke engines was applied by using solenoid valves and a DC- motor to start the engine, in this research it is proven that the engine can work with six stroke engine by using the same conventional mechanical valve systems and the conventional engine starter.

\section{REFERENCES}

[1] Pandiyarajan V., Pandian M. C., Malan E., Velraj R. and Seeniraj R.V., "Experimental Investigation on Heat Recovery from Diesel Engine Exhaust Using Finned Shell and Tube Heat Exchanger and Thermal Storage System", Applied Energy, Vol. 88 (2011). 
[2] Thermoelectric Systems for Greener Vehicles, www.greencarcongress.com (accessed 27/11/2011).

[3] Conklina J. C. and Szybist J. P., "A Highly Efficient Six-Stroke Internal Combustion Engine Cycle with Water Injection for In-Cylinder Exhaust Heat Recovery", Energy, Volume 35, Issue 4, pp. 1658-1664 (2010).

[4] Andrew De Jong, team 6 stroke, https://knightvision.calvin.edu (accessed 14/2/2012).

\section{ACKNOWLEDGEMENT}

The authors would like to thank automotive excellence center (AEC), University Malaysia Pahang to provide the fund used to complete this work. 